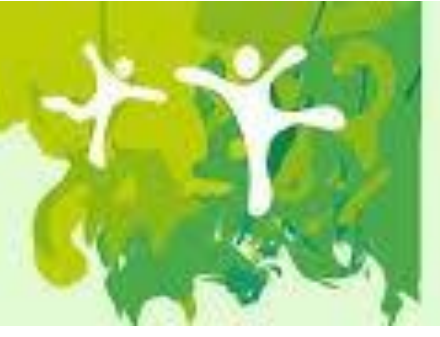

\title{
ALTERAÇOES POSTURAIS EM CRIANÇAS E ADOLESCENTES APOS TRANSPLANTE RENAL
}

\section{Pôster}

Autores deste trabalho:

Maria Cristina de Andrade: UNIFESP-EPM

GAMA ACR: UNIFESP-EPM

MANGIA C: UNIFESP-EPM

BRECHERET AP: UNIFESP-EPM

GESSULLO ADV: UNIFESP-EPM

MEDINA JO: UNIFESP EPM

DINIZ D: UNIFESP-EPM

Área do Trabalho: Pediatria

Número de inscrição: 5597

Data da submissão:01/09/2016 às 10:40

\section{Justificativa}

Com o aumento da sobrevida dos pacientes e do enxerto na última década, a reabilitação da criança submetida ao transplante renal passou a ser de primordial importância.

\section{Objetivo(s)}

Avaliar a presença e tipo das alterações músculo-esqueléticas nas crianças e adolescentes no pós-transplante renal.

\section{Método(s)}

Avaliação de 41 pacientes durante o período de abril a novembro/2007, com determinação da força muscular, desvios ortopédicos, e medidas de peso e estatura. Os dados: idade, clearance de creatinina, etiologia da doença renal crônica (DRC), tempo e tipo de tratamento prévio e tempo de transplante foram obtidos do prontuário.

\section{Resultado(s)}


Os pacientes tinham idade entre 6 e 21 anos, com média de 13anos (IC95\%=11,914,3anos), não havendo diferença significativa entre os gêneros. Os valores médios dos escores $\mathrm{z}$ dos indicadores P/I, E/I e IMC/I foram:-1,22, -2,29 e 2,23 respectivamente. Todos os pacientes apresentaram alteração no alinhamento da cabeça e das escápulas e, a média do número de alterações ortopédicas/paciente foi de 9,68. A força muscular foi considerada boa apenas para 12,20\% dos pacientes. Em relação à etiologia, o diagnóstico mais freqüente foi uropatia $(41,5 \%)$,. Antes do transplante renal, $56,1 \%$ dos pacientes realizavam hemodiálise, 36, 6\% diálise peritonial e 7,3\% tratamento conservador. $24 \%$ dos pacientes realizaram o transplante renal há menos de 1 ano, 29\% entre 1-2 anos e $47 \%$ entre 3-7 anos.

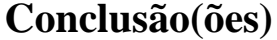

As alterações músculo-esqueléticas foram observadas em todos os pacientes. Estas alterações provavelmente se iniciaram durante os estágios da DRC, reforçando a necessidade de intervenção e tratamento precoces. 